\title{
DISTRIBUIÇÃO DO SISTEMA RADICULAR DA GOIABEIRA 'RICA’ PRODUZIDA A PARTIR DE ESTAQUIA HERBÁCEA ${ }^{1}$
}

\author{
ANTONIO AUGUSTO FRACARO² \& FERNANDO MENDES PEREIRA ${ }^{3}$
}

\begin{abstract}
RESUMO - O conhecimento da distribuição do sistema radicular de plantas, principalmente de perenes, não é muito estudado, devido a inúmeros fatores, dentre os quais, a dificuldade inerente ao método de amostragem. A presente pesquisa objetivou conhecer o sistema radicular da goiabeira através do método de escavação. Utilizando jatos de água, retirou-se a terra até um volume de $10 \mathrm{~m}^{3}(5 \times 5 \times 0,4 \mathrm{~m})$, subdivididos em paralelepípedos de $0,1 \mathrm{~m}^{3}(0,5 \times 0,5 \times 0,4 \mathrm{~m})$, expondo o sistema radical da goiabeira 'Rica'. Verificou-se um vigoroso sistema radicular sem a caracterização da raiz principal e com distribuição homogênea, grande número de raízes primárias, proporcionado pela adequada formação de mudas, através de estaquia herbácea. Termos de indexação: raiz, sistema radicular, Psidium guajava.
\end{abstract}

\section{DISTRIBUTION OF ROOT SYSTEM OF GUAVA "RICA" PLANTS OBTAINED FROM HEBACEOUS CUTTINE}

ABSTRACT - The knowledge of the distribution of the plant root system, mainly of permanent plants, is not well studied in function to several factors, amongst them, the inherent difficulty to collect samples. The present research objectified to know the root system through the excavation method, using water jet, it was removed the soil volume of $10 \mathrm{~m}^{3}(5 \times 5 \times 0.4 \mathrm{~m})$, subdivided in $0.1 \mathrm{~m}^{3}(0.5 \times 0.5 \times 0.4 \mathrm{~m})$ showing the root system of the 'Rica' guava. It was verified a vigorous radical system without the characteristics of the main root and with homogeneous distribution, great number of primary root, provided by the adjusted formation of seedling, through herbaceous cuttings.

Index Terms: root system, Psidium guajava .

A importância do estudo do sistema radicular das espécies vegetais utilizadas na agricultura, sua distribuição, extensão e atividade, é incontestável e fundamental para o entendimento científico da produção agrícola. As raízes das plantas têm distribuição variável com as espécies e cultivares, idade da planta e as características químicas e físicas do solo, os tratos culturais e as condições fitossanitárias. O conhecimento sobre a quantidade, qualidade e distribuição das raízes é útil na produção agrícola para fornecer informações sobre localização de adubos, espaçamento, culturas intercalares, manejo do solo e irrigação. Trabalho realizado por Cintra \& Neves (1996) relataram dificuldades inerentes aos métodos de amostragem para o pleno conhecimento do sistema radicular, especialmente de plantas perenes.

No caso específico da goiabeira (Psidium guajava L.), as plantas tradicionalmente são produzidas através de sementes, sendo posteriormente enxertadas ou não. Plantas assim formadas apresentam sistema radicular pivotante. Entretanto, no Brasil, a propagação de goiabeira, a partir da década de 1990, é realizada preferencialmente através de estacas herbáceas, enraizadas em câmaras de nebulização (Pereira \& Nachtigal, 1997; Pereira, 1995).

O conhecimento da distribuição do sistema radicular de plantas de goiabeira assim formadas, que já atinge no Brasil o número superior a 2.500.000 plantas, é fundamental para o estabelecimento de práticas culturais nos pomares assim constituídos.

O objetivo do trabalho é conhecer o sistema radicular de plantas de goiabeira formadas por estaca herbácea.

O estudo foi conduzido no pomar experimental da FCAV-UNESP, Câmpus de Jaboticabal, o qual não apresenta sistema de irrigação, e as adubações são realizadas esporadicamente dentro da projeção da copa, com espaçamento de 7 x $5 \mathrm{~m}$. O solo é classificado como Latossolo Vermelho eutroférrico e utilizou-se uma única planta da cultivar Rica obtida por estaquia herbácea de doze anos de idade.

'Rica' é uma cultivar obtida no programa de melhoramento genético da goiabeira da FCAV- Jaboticabal-UNESP, cujas plantas são vigorosas e muito produtivas, atingido espaçamento próximo de $35 \mathrm{~m}^{2}$ (Pereira, 1984; 1995).

Em junho de 2002, no pomar experimental, após a seleção de uma planta da cultivar Rica, delimitou-se uma área de $25 \mathrm{~m}^{2}(5 \times 5 \mathrm{~m}) \mathrm{em}$ torno da planta.

Após demarcação, esta área foi subdividida em quadros de
$0,25 \mathrm{~m}^{2}$, enterrando-se estacas de ferro de $60 \mathrm{~cm}$ de comprimento nos vértices de cada quadro. Uma fita plástica foi ligada a todas as estacas, quadriculando a área experimental em 100 subáreas (Figura 1).

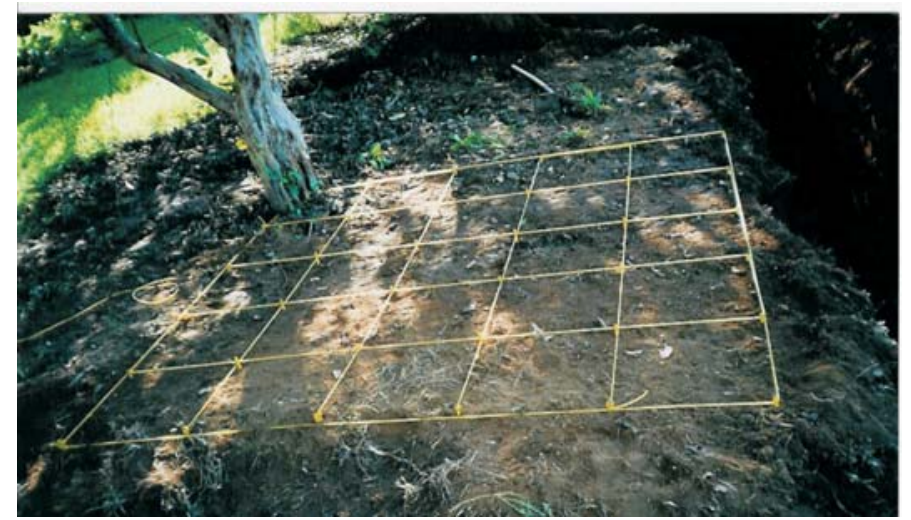

FIGURA 1 - Demarcação de quadros $0,25 \mathrm{~m}^{2}$, através de fita plástica, em um quarto da planta de goiabeira 'Rica' na FCAV-UNESP, Jaboticabal, 2002.

Com o objetivo de expor o sistema radicular, procedeu-se à remoção da terra com jatos de água $\left(3,5 \mathrm{Kgf.cm}^{-2}\right.$ de pressão e 14.400 L.h ${ }^{1}$ de vazão). O transporte da água para o local foi realizado com um caminhão pipa (8.000 litros), sendo utilizados 168.000 litros de água para remover toda a terra até à profundidade de $40 \mathrm{~cm}$ (Figura 2). Preliminarmente à aplicação, com auxílio de uma retroescavadeira, abriuse uma valeta de 3 metros de profundidade para o escoamento da água. À medida que a terra era retirada, amarravam-se as raízes nas fitas plásticas, para a sustentação das mesmas na posição original.

As raízes foram coletadas até a profundidade de $0,4 \mathrm{~m}$ por quadro, formando paralelepípedos de $0,1 \mathrm{~m}^{3}$, para avaliação do seu volume e peso seco. O volume das raízes foi medido em cuba graduada $(0,1 \times 0,1 \times 0,5 \mathrm{~m})$, pelo deslocamento da água.

$\mathrm{O}$ peso seco foi realizado através da secagem das raízes em estufa a $65^{\circ} \mathrm{C}$ até peso constante, e utilizou-se uma balança digital com precisão de 2 centésimos de grama.

Para determinação destes dois parâmetros, as raízes foram

\footnotetext{
${ }^{1}$ (Trabalho 075/2003). Recebido: 04/07/2003. Aceito para publicação: 02/04/2004.

${ }^{2}$ Doutorando em Agronomia, Departamento de Produção Vegetal, Universidade Estadual Paulista-UNESP, Faculdade de Ciências Agrárias e Veterinárias- FCAV, Campus de Jaboticabal, Rodovia de Acesso Prof. Paulo Donato Castellane, s/n, CEP14884-900, Jaboticabal-SP. Fone: (17) 3621-6884. E-mail: fracaro@melfinet.com.br ${ }^{3}$ Dr., Prof. Titular Aposentado, Departamento de Produção Vegetal, FCAV/UNESP, Campus de Jaboticabal, Rodovia de Acesso Prof. Paulo Donato Castellane, s/n, CEP14884-900 Jaboticabal, SP.
} 


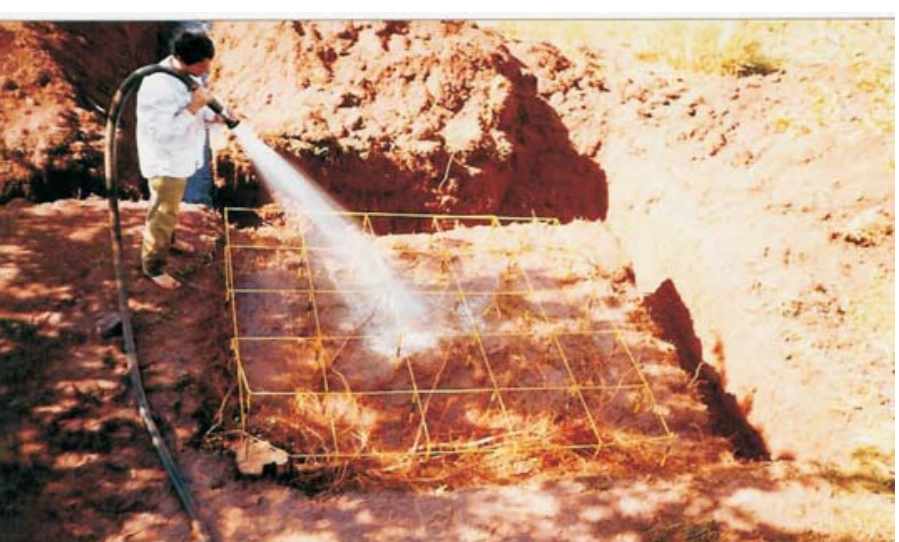

FIGURA 2 - Remoção da terra com jatos de água até a profundidade de $40 \mathrm{~cm}$ em um quarto da planta de goiabeira 'Rica' na FCAVUNESP, Jaboticabal, 2002

separadas e classificadas como grossas (acima de $2,8 \mathrm{~mm}$ ) e finas (igual ou abaixo de $2,8 \mathrm{~mm}$ de diâmetro).

O peso seco total de raízes no volume de $10 \mathrm{~m}^{3}(5 \times 5 \times 0,4 \mathrm{~m})$ foi de $16,82 \mathrm{~kg}$, sendo $14,20 \mathrm{~kg}$ de raízes grossas e $2,62 \mathrm{~kg}$ de raízes finas, ou seja, $84,39 \%$ de raízes grossas e $15,61 \%$ raízes finas.

A presente pesquisa não evidenciou a característica do sistema radicular pivotante, porém apresentou várias raízes espessas sem a caracterização da raiz principal da cultivar Rica, formado através de estacas herbáceas com abundante quantidade de raízes distribuídas em todas as partes do solo.

Verificou-se, através do peso seco das raízes finas, uma distribuição homogênea do sistema radicular, sendo maiores os valores encontrados nos paralelepípedos próximos do tronco da planta.

Observou-se que o sistema radicular desenvolveu-se além dos $25 \mathrm{~m}^{2}$ estudados, sendo maior o desenvolvimento radicular no sentido da linha de plantio.

A distribuição do sistema radicular da cultivar Rica, medido através do peso seco total das raízes, apresentou em média 168,20 g.0,1 $\mathrm{m}^{-}$ ${ }^{3}$, sendo o menor valor observado de 12,37 g. $0,1 \mathrm{~m}^{-3}$ e o maior valor observado foi de $2.180,52$ g. $0,1 \mathrm{~m}^{-3}$.

A distribuição do sistema radicular da cultivar Rica medido através do peso seco das raízes grossas apresentou em média 141,94 g. $0,1 \mathrm{~m}^{-3}$, sendo o menor valor observado de $1,71 \mathrm{~g} .0,1 \mathrm{~m}^{-3} \mathrm{e}$ o maior valor observado foi de $2.154,01 \mathrm{~g} .0,1 \mathrm{~m}^{-3}$.

As raízes primárias (desenvolvidas a partir da estaca) apresentaram um grande desenvolvimento, com abundante ramificação.

A distribuição do sistema radicular da cultivar Rica medido através do peso seco das raízes finas apresenta melhor uniformidade de distribuição, estando numa faixa média de 0,1 a 50 g. $0,1 \mathrm{~m}^{-3}$ (sendo a média de 26,6 g. $0,1 \mathrm{~m}^{-3}$ ). Na Figura 3 , verifica-se que as faixas de 0,1 a 20 e 20,1 a 50 g. $0,1 \mathrm{~m}^{-3}$ representam $94 \%$ dos paralelepípedos amostrados.

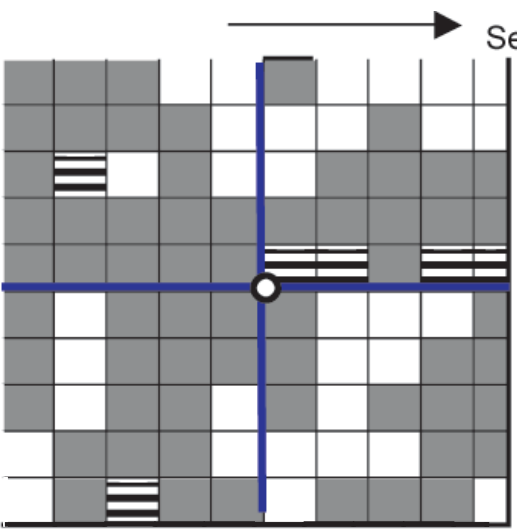

Sentido da linha de plantio

Legenda*

$0,1-20$
$20,1-50$
$50,1-70$

acima de 70,1

Centro da planta

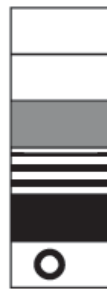

*Peso (g. $\left.0,1 \mathrm{~m}^{-3}\right)$

*Volume $\left(\mathrm{cm}^{3} .0,1 \mathrm{~m}^{-3}\right)$

FIGURA 3 - Peso seco de raízes finas (g) por paralelepípedos de $0,1 \mathrm{~m}^{3}$ da goiabeira 'Rica', propagada por estaquia herbácea na FCAV - UNESP, Jaboticabal, 2002
As raízes ativas (finas) foram encontradas em grande número e uniformemente distribuídas por toda a área estudada (Figura 4 e 5).

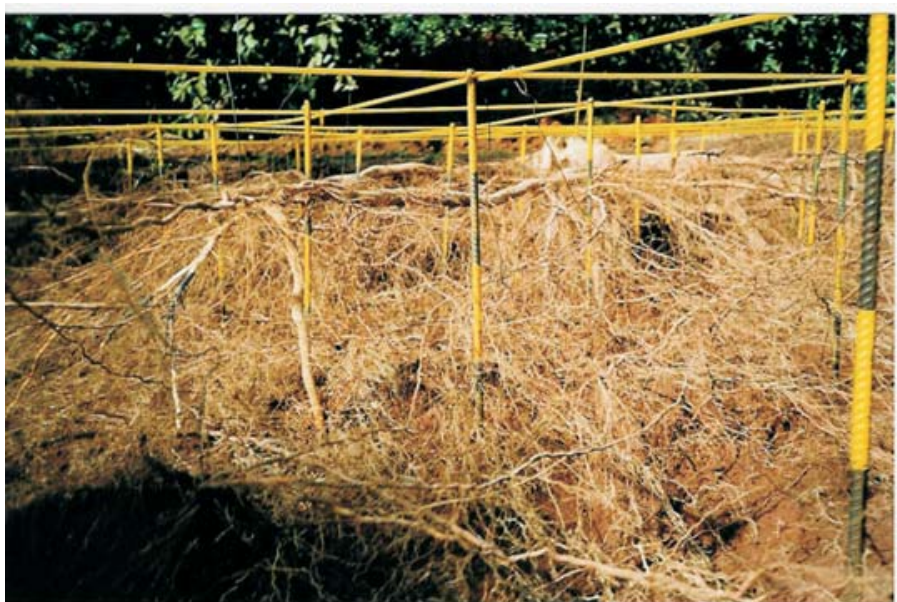

FIGURA 4 - Distribuição do sistema radicular até a profundidade de 40 $\mathrm{cm}$, da goiabeira 'Rica' propagada por estaquia herbácea, na FCAV-UNESP, Jaboticabal, 2002.

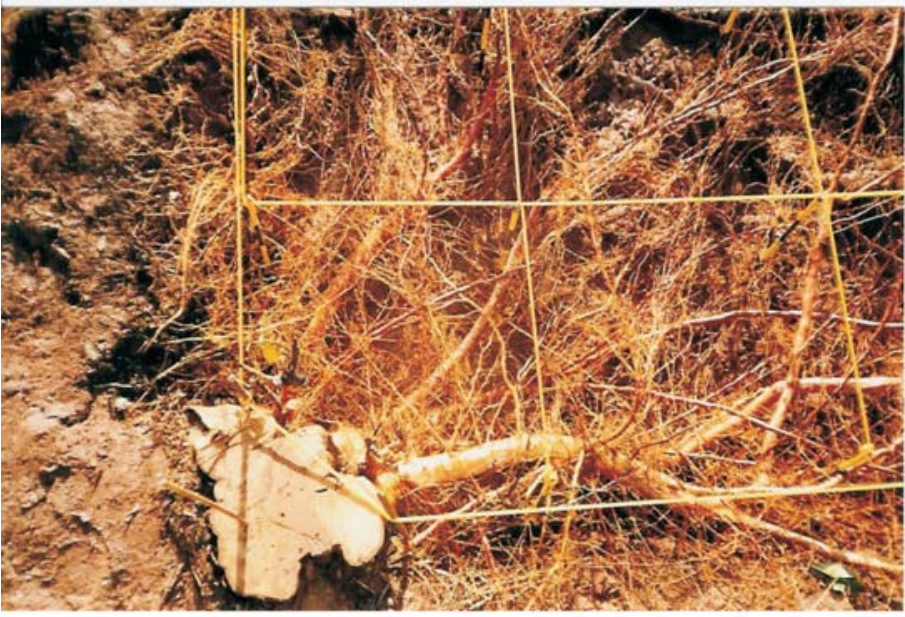

FIGURA 5 - Detalhe do sistema radicular, mostrando a distribuição das raízes finas e grossas, próximas do tronco da goiabeira 'Rica', na FCAV-UNESP, Jaboticabal, 2002.

A planta de goiabeira estudada, produzida por estaca herbácea, não apresentou sistema radicular pivotante, porém apresentou diversas raízes espessas com aprofundamento em volta do tronco (raio de 0,80 $\mathrm{m}$ ), o que provavelmente conferiu a mesma grande resistência ao tombamento.

$\mathrm{O}$ aprofundamento do sistema radicular possibilita às plantas melhores condições de atravessar períodos de estresse hídrico, diminuindo as perdas de produção (Neves \& Medina, 1999).

O volume total de raízes no volume de $10 \mathrm{~m}^{3}$ foi de $31.550 \mathrm{~cm}^{3}$, sendo $27.410 \mathrm{~cm}^{3}$ de raízes grossas e $4.140 \mathrm{~cm}^{3}$ de raízes finas, ou seja, $86,88 \%$ de raízes grossas e $13,12 \%$ raízes finas.

A distribuição do sistema radicular da cultivar Rica medido através do volume das raízes grossas apresentou em média $27,41 \mathrm{~cm}^{3} .0,1 \mathrm{~m}^{-3}$.

A distribuição do sistema radicular da cultivar Rica medido através do volume das raízes finas apresenta melhor uniformidade de distribuição, com média de $41,38 \mathrm{~cm}^{3} .0,1 \mathrm{~m}^{-3}$, estando $72 \%$ dos paralelepípedos amostrados nas faixas de 20,1 a 50 e 50,1 a $70 \mathrm{~cm}^{3} .0,1 \mathrm{~m}^{-}$ ${ }^{3}$, o qual se verifica na Figura 6.

Segundo Atkinson (1980), a variabilidade dos resultados ocorre porque o solo é heterogêneo e o sistema radical desvia de zonas menos favoráveis, seguindo caminhos de menor resistência em fendas e canais da fauna do solo e de material orgânico em decomposição. 


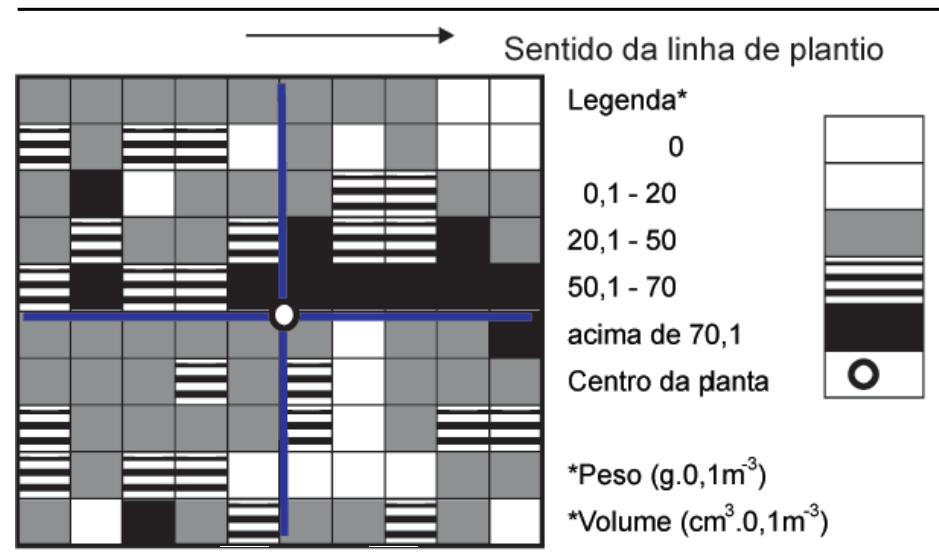

FIGURA 6 - Volume $\left(\mathrm{cm}^{3}\right)$ de raízes finas por paralelepípedos de $0,1 \mathrm{~m}^{3} \mathrm{da}$ goiabeira 'Rica', propagada por estaquia herbácea na FCAV - UNESP, Jaboticabal, 2002.

A distribuição do sistema radicular encontrado na goiabeira é garantia de que mudas formadas a partir de estacas herbáceas têm condições plenas de explorar um grande volume de solo, permitindo ótima absorção de nutrientes e água, obtendo produções satisfatórias.

Na distribuição do sistema radicular, é observado maior volume de raízes nas áreas de menor incidência de ervas daninhas (grama) e, conseqüentemente, nas áreas de maior acúmulo de material orgânico, observa-se maior volume de raízes. Em estudo realizado por Neves et al. (1998), observou-se que a interrupção brusca da presença de raízes de plantas cítricas coincidiu com início da presença do sistema radicular da cobertura vegetal (Arachis prostrata Bong. ex Benth.), provocando o aprofundamento do sistema radicular da planta.

Este estudo evidencia que, nas práticas de adubação, a localização do fertilizante não deverá ser feita em linha na projeção da copa, mas por toda a superfície em torno da mesma.

Em implantação de pomares com irrigação localizada, este estudo é fundamental para a localização dos microaspersores e/ou gotejadores que devem ser distribuídos por toda a linha de plantio, pois um grande número de raízes ativas está distribuído nesta faixa do solo.

Um eficiente sistema radicular é possibilitado por uma adequada formação de mudas. Na planta estudada, pode-se observar que através da estaquia herbácea de goiabeira foi possível obter mudas com adequado número de raízes primárias e, a partir destas, excelente sistema radicular.

\section{REFERÊNCIAS BIBLIOGRÁFICAS}

ATKINSON, D. The distribution and effectiveness of the roots of trees crops. Horticultural Reviews, New York, v. 2, p. 424-490, 1980.

CINTRA, F.L.D.; NEVES, C.S.V.J. Aspectos metodológicos do estudo do sistema radicular de plantas perenes através de imagens. Boletim informativo da Sociedade Brasileira de Ciência de Solo, v. 21, n. 3, p. 91-94, 1996.

NEVES, C. S. V. J.; DECHEN, A. R.; FELLER, C.; SAAB, O. J. G. A.; PIEDADE,S. M. S. Efeito do manejo do solo no sistema radicular de Tangerineira "PONCÃ" enxertada sobre o limoeiro 'CRAVO' em Latossolo Roxo. Revista Brasileira de Fruticultura, Cruz das Almas, v. 20, n. 2, p. 246-253, 1998.

NEVES, C.S.V. J.; MEDINA, C. C. Distribuição de raízes de citros em latossolo roxo. In: WORKSHOP SOBRE SISTEMA RADICULAR;METODOLOGIAS E ESTUDODE CASOS, 1999, Aracaju. Anais... Aracaju: EMBRAPA Tabuleiros Costeiros, 1999. p. 153-166.

PEREIRA, F.M. Rica e Paluma: novas cultivares de goiabeira. In: CONGRESSO BRASILEIRO DE FRUTICULTURA, 7., 1983, Florianópolis. Anais... Florianópolis:SBF/EMPASC, 1984. p. 524-528.

PEREIRA, F.M. Cultura da goiabeira Jaboticabal: Funep, 1995. $47 \mathrm{p}$.

PEREIRA, F.M.; NACHTIGAL, J.C. Propagação da goiabeira. In: SIMPÓSIO BRASILEIRO SOBREACULTURADA GOIABEIRA, 1. 1997, Jaboticabal. Anais... Jaboticabal:Funep, 1997. p. 17-32. 